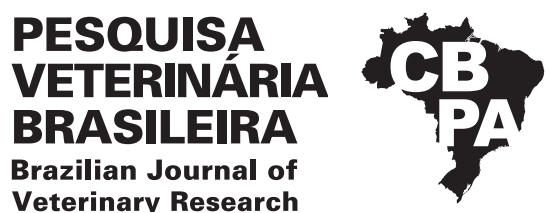

Pesq. Vet. Bras. 41:e06825, 2021

DOI: $10.1590 / 1678-5150-P V B-6825$

Original Article

Small Animal Diseases

ISSN 0100-736X (Print)

ISSN 1678-5150 (Online)

\title{
The need for opioid in the postoperative analgesia of dogs undergoing hemilaminectomy due to intervertebral disc extrusion ${ }^{1}$
}

\author{
Dênis A. Ferrarin², Marcelo L. Schwab², Mathias R. Wrzesinski² ${ }^{2}$ Angel Ripplinger ${ }^{4}$, \\ Júlia S. Rauber ${ }^{2}$, Anne G.C. Santos ${ }^{3}$, Graciane Aiello ${ }^{4}$ and Alexandre Mazzanti*5 (i)
}

\begin{abstract}
Ferrarin D.A., Schwab M.L., Wrzesinski M.R., Ripplinger A., Rauber J.S., Santos A.G.C, Aiello G. \& Mazzanti A. 2021. The need for opioid in the postoperative analgesia of dogs undergoing hemilaminectomy due to intervertebral disc extrusion. Pesquisa Veterinária Brasileira 41:e06825, 2021. Serviço de Neurologia e Neurocirurgia Veterinária, Departamento de Clínica de Pequenos Animais, Universidade Federal de Santa Maria, Prédio 97, Camobi, Santa Maria, RS 97105-900, Brazil. E-mail: alexamazza@yahoo.com.br

The aim of this study was to evaluate the postoperative analgesic effect of protocols with and without the opioid methadone in dogs with intervertebral disc extrusion undergoing decompressive surgery. Sixteen paraplegic dogs with preserved nociception underwent hemilaminectomy/disc fenestration and were randomly assigned to two groups. The analgesic protocol consisted of methadone, meloxicam and dipyrone in Group I (G1), and meloxicam and dipyrone in Group II (G2). The animals were blindly assessed by two observers, using the visual analogue scale (VAS) and the short-form Glasgow Composite Measure Pain Scale (CMPS-SF). Assessments occurred every 2 hours during first 24 hours post-surgery, and every 4 hours afterwards. There was no statistical difference among groups regarding pain scores or analgesic rescues. Both analgesic protocols provided analgesia in the initial 48 hours postoperatively, demonstrating that opioids are not necessary in the postoperative period of dogs undergoing hemilaminectomy and disc fenestration.
\end{abstract}

INDEX TERMS: Postoperative analgesia, dogs, hemilaminectomy, intervertebral disc, metamizole, pain, opioid-free analgesia, neurosurgery, methadone.

RESUMO.- [A necessidade de opioide na analgesia pósoperatória de cães submetidos à hemilaminectomia devido à extrusão do disco intervertebral.] 0 objetivo deste estudo foi avaliar a analgesia pós-operatória de protocolos com e sem o opioide metadona em cães com extrusão de disco intervertebral submetidos à descompressão cirúrgica. Dezesseis cães paraplégicos com presença de nocicepção

\footnotetext{
${ }^{1}$ Received on March 1, 2021

Accepted for publication March 23, 2021.

${ }^{2}$ Graduate Program in Veterinary Medicine (PPGMV), Serviço de Neurologia e Neurocirurgia Veterinária, Centro de Ciências Rurais (CCR), Universidade Federal de Santa Maria (UFSM), Camobi, Santa Maria, RS 97105-900, Brazil.

${ }^{3}$ Curso de Medicina Veterinária, Centro de Ciências Rurais (CCR), Universidade Federal de Santa Maria (UFSM), Camobi, Santa Maria, RS 97105-900, Brazil.

${ }^{4}$ Universidade do Oeste de Santa Catarina (UNOESC), Campus Xanxerê, Rua Dirceu Giordani 696, Jardim Taruma, Xanxerê, SC, 89820-000, Brazil.

${ }^{5}$ Serviço de Neurologia e Neurocirurgia Veterinária, Departamento de Clínica de Pequenos Animais, Centro de Ciências Rurais (CCR), Universidade Federal de Santa Maria (UFSM), Camobi, Santa Maria, RS 97105-900, Brazil.

*Corresponding author: alexamazza@yahoo.com.br
}

foram submetidos à hemilaminectomia/fenestração de disco e distribuídos aleatoriamente em dois grupos. No Grupo I (G1), o protocolo analgésico consistiu em metadona, meloxicam e dipirona e, no Grupo II (G2), por meloxicam e dipirona. Os pacientes foram avaliados de maneira cega por dois avaliadores, com base na escala visual analógica (EVA) e na escala simplificada composta de dor de Glasgow (CMPS-SF). As avaliações ocorreram a cada 2 horas durante as primeiras 24 horas de pós-operatório e, por mais 24 horas, a cada 4 horas. Não houve diferença estatística entre os grupos avaliados em relação à escores de dor e nem a necessidade de resgate analgésico. Ambos os protocolos promoveram analgesia nas 48 horas iniciais de pós-operatório, demonstrando não haver a necessidade do uso de opioide em cães submetidos à hemilaminectomia e fenestração de disco.

TERMOS DE INDEXAÇÃO: Hemilaminectomia, disco intervertebral, caninos, metamizol, dor, analgesia livre de opioide, neurocirurgia, metadona. 


\section{INTRODUCTION}

The intervertebral disc extrusion (IVDE) is the most prevalent neurological disease in dogs, occurring mainly in chondrodystrophic breeds (Brisson 2017). Hemilaminectomy associated to disc fenestration is one of the recommended therapeutic options for IVDE. In addition to the pain caused by the IVDE compression on the spinal cord, nerve roots, meninges, annulus fibrosus, epaxial musculature and ligamentous structures (Platt 2004), the surgical procedure itself also elicit significant pain. Mathews et al. (2014) anecdotally classified the perceived pain associated to spinal procedures, including hemilaminectomy, as being intense. Therefore, prolonged use of opioids, such as morphine, methadone, or fentanyl associated with nonsteroidal anti-inflammatory drugs (NSAIDs) and dipyrone may be recommended (Fantoni \& Mastrocinque 2010).

Nevertheless, the use of opioids in dogs is associated with mild to moderate adverse effects, such as reduced gastrointestinal motility, emesis, dysphoria, myosis, respiratory depression and sedation (Kukanich \& Wiese 2015), which may interfere with the quality of patient's recovery, and delay its hospital discharge. While there are drugs to alleviate these adverse effects, analgesic protocols without opioids were already tested in dogs undergoing other procedures causing severe pain, such as orthopedics, promoting an effective analgesia (Deneuche et al. 2004, Gruet et al. 2011). In addition, it is known that neuropathic pain is not effectively controlled by opioid medications (Muir III 2015).

There is still no consensus on which drug or protocol is the most effective for the postoperative analgesia in dogs undergoing spinal procedures, since both opioids and nonopioids drugs (non-opioid analgesics, NSAIDs, gabapentin, pregabalin, methocarbamol, medetomidine, diazepam, lidocaine) have already been described for this purpose (Forterre et al. 2008, Aghighi et al. 2012, Barker et al. 2013, Taylor-Brown et al. 2015, Giudice et al. 2017, Re Bravo et al. 2018, Ripplinger et al. 2018, Schmierer et al. 2020).

Therefore, the aim of this study was to evaluate the pain control of two postoperative analgesic protocols, with and without the opioid methadone, in dogs with thoracolumbar and lumbar IVDE undergoing hemilamectomy and disc fenestration, during the first 48 hours. Our hypothesis is that the decompression achieved by these procedures is sufficient to reduce the patient's pain to a level that is manageable through a postoperative opioid-free analgesic protocol.

\section{MATERIALS AND METHODS}

This study was conducted as a prospective, blinded and randomized clinical trial. Sixteen dogs were included, regardless of gender, age, and weight, cared by the neurology and neurosurgery department of a veterinary teaching hospital and with a definitive diagnosis of thoracolumbar or lumbar IVDE. The study was conducted under approval of the Institutional Ethics Committee on Animal Use of the "Universidade Federal de Santa Maria" (4457011217) and signed owner consent. All patients were paraplegic with preserved nociception and had a myelogram exam. The time elapsed from onset of paraplegia to surgery ranged from two to seven days. A presumptive diagnosis of extradural spinal cord compression was made, and confirmation of intervertebral disc extrusion was achieved during surgery by removing disc material within the vertebral canal. Prior to surgery, the patients received analgesia with dipyrone $(25 \mathrm{mg} /$ $\mathrm{kg}$, subcutaneously - SC). During the image exam, the analgesia was provided with fentanyl boluses $(2 \mu \mathrm{g} / \mathrm{kg}$, intravenously - IV).

In the pre and postoperative periods, the dogs were kept in a kennel, with a temperature between $22^{\circ} \mathrm{C}$ and $24^{\circ} \mathrm{C}$, in individual cages, being manipulated and medicated by the same professionals. Food and water were offered ad libitum. Before anesthesia, animals were fasted for eight hours from solid food, and six hours from water. Premedication with Diazepam $(0.5 \mathrm{mg} / \mathrm{kg}$, IV) was immediately followed by induction of anesthesia with propofol ( $5 \mathrm{mg} / \mathrm{kg}$, IV). After endotracheal intubation, anesthesia was maintained with isoflurane in oxygen, to effect.

Intraoperative analgesia was performed with continuous infusion of fentanyl $(10 \mu \mathrm{g} / \mathrm{kg} / \mathrm{h}$, IV, preceded by a bolus of $2 \mu \mathrm{g} / \mathrm{kg}$, IV), initiated after the endotracheal intubation. Cephalotin sodium $(30 \mathrm{mg} / \mathrm{kg}, \mathrm{IV})$ was given as a prophylactic antibiotic in all patients and repeated every two hours until the end of surgery. Hemilaminectomy and disc fenestration were performed according to the technique described by Shores (2017) and Brisson (2017), respectively. Just one intervertebral space and disc were operated in each dog.

After the surgical procedure, all dogs were randomly assigned by an online software ${ }^{6}$ to two groups of equal number, according to a predetermined analgesic protocol. The analgesic protocol of Group I (G1) consisted of methadone $(0.3 \mathrm{mg} / \mathrm{kg}$, every 6 hours, SC) for 24 hours), meloxicam (first dose of $0.2 \mathrm{mg} / \mathrm{kg}$ and a second one of $0.1 \mathrm{mg} / \mathrm{kg}$, after $24 \mathrm{~h}, \mathrm{SC}$ ) and dipyrone (25mg/kg, every 8 hours, SC, for 2 days). The Group II (G2) analgesic protocol was composed by meloxicam and dipyrone (same dosages and administrations cited for Group I).

At the end of surgery, the continuous infusion of fentanyl was stopped and the first analgesic administration based on the group protocol was performed. Cryotherapy was also performed in all animals, after the relevant pain assessment, using crushed ice packs directly on the incision, every 6 hours, for 20 minutes.

Postoperative analgesia was evaluated using the visual analogue scale (VAS) (Gruet et al. 2011) and the short-form Glasgow Composite Measure Pain Scale (CMPS-SF) (Reid et al. 2007), in this order, by two experienced observers, blinded to the analgesic group and to each other. The VAS is composed by a $100 \mathrm{~mm}$ line, where $0 \mathrm{~mm}$ means no pain, and $100 \mathrm{~mm}$ represents severe pain. The CMPS-SF is a four-section checklist, based on visual assessments and wound palpation. Since the mobility section of the original scale could not be carried out, the maximum score on this scale was 20, as already mentioned by Schmierer et al. (2020) and Re Bravo et al. (2018).

The first assessment (Baseline) was done immediately before premedication, with the patient under only dipyrone analgesia. The second assessment (T0) occurred 30 minutes after the end of surgery. Subsequent assessments (T2, T4, T6, T8, T10, T12, T14, T16, T18, T20, T22, T24) were done every two hours until 24 hours were completed, and then every 4 hours (T28, T32, T36, T40, T44, T48) until the total evaluation period of 48 hours was completed.

Rescue analgesia was planned for scores higher than five centimeters in VAS or scores equal to or higher than six on the CMPS-SF. The limit for analgesic rescue in this study was chosen above that recommended by Reid et al. (2007) (5), because the original GCMPS was reported to be inflexible for behavioral manifestations (Barker et al. 2013). In addition, other authors have used the CMPS-SF with limits for analgesic rescue higher than the originally mentioned by Reid et al. (2007), for the same procedure

\footnotetext{
6 Available at <random.org >
} 
(Aghighi et al. 2012, Giudice t al. 2017, Schmierer et al. 2020). The rescue protocol included morphine hydrochloride $(0.3 \mathrm{mg} / \mathrm{kg}, \mathrm{IM})$, when the predetermined threshold was reached in any of the scales. In rescue cases, the animals would undergo further assessments every hour until they reached scores below the scales' threshold. Adverse effects or complications in the postoperative period were recorded and the necessary care was given by the clinician.

Data were tested for normality using the Shapiro-Wilk test. Age and weight data showed a parametric distribution. Thus, an unpaired t-test was performed for comparison between groups, and the data were expressed as mean \pm standard deviation (SD). Differences were considered significant when $p<0.05$. Data from pain assessments were considered non-parametric. For the temporal analysis (comparison of the behavior of a data over time), the Friedman test was used, followed by Dunn's post-test. For the comparison between groups in each time, the Mann-Whitney test was used. The data are presented as descriptive statistics of minimum value, $25 \%$ percentile, median, $75 \%$ percentile and maximum value for each group at each time. The correlation between observers was tested using the Intra-class correlation coefficient.

\section{RESULTS}

Of the 16 evaluated patients, nine (56.25\%) were females and seven $(43.75 \%)$ were males. The mean age was $7.03 \pm 2.13$ years, and the mean weight was $9.3 \pm 5.25 \mathrm{~kg}$. No statistical differences were seen in sex, age, and body weight between groups. The analgesic protocol group, breed, age, weight, and medullary compression site of the 16 dogs undergoing hemilaminectomy and fenestration are shown in Table 1.

Regarding the correlation degree among observers, it was considered substantial in the VAS (0.76) and near-perfect in the CMPS-SF (0.83). There was no significant difference $(p<0.05)$ between groups assessed for pain scores by the VAS (Fig.1-2), except in T48 assessment. There were no analgesic rescue administrations according to this scale. The highest postoperative median according to the VAS occurred in the animal 15 (G2, T0) (39 \pm 7.07$)$.

The analgesia assessment by the CMPS-SF (Fig.1-2) also did not show statistical difference between groups. Rescue analgesia was not administered according to this scale. The highest number of scores 5 , close to the rescue limit established
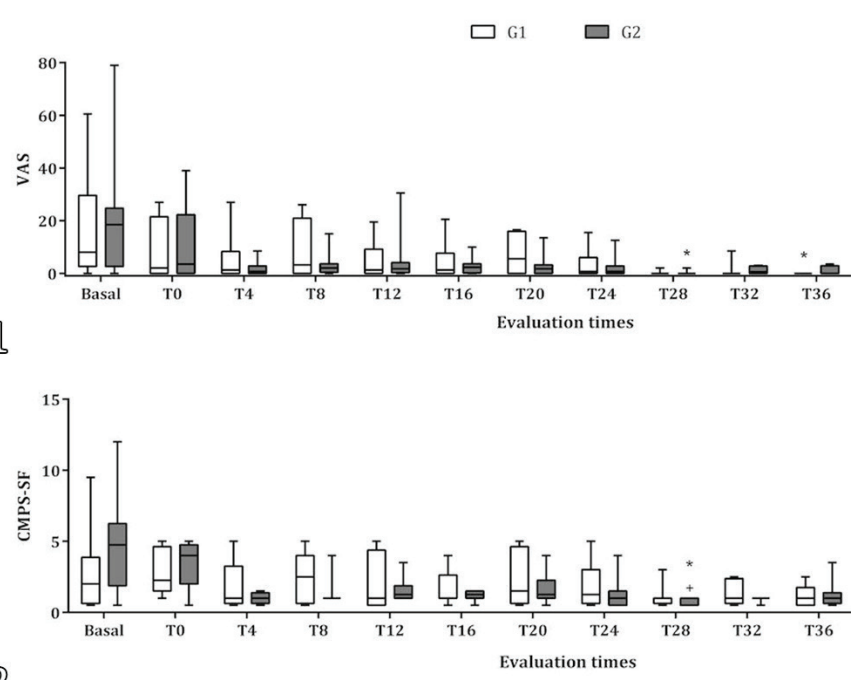

2

Fig.1-2. Median pain scores by group, obtained from (1) the visual analogue scale (VAS) (mm) and (2) the short-form Glasgow Composite Measure Pain Scale (CMPS-SF). G1 = Methadone, Meloxicam, and Dipyrone; G2 = Meloxicam and Dipyrone. Statistical difference when compared to the Baseline assessment in the same group $\left(^{*}\right)$, Statistical difference between groups (\#), statistical difference for $\mathrm{T} 0$, in the same experimental group (+). Assessment times T2, T6, T10, T14, T18 and T22 were not described for layout purposes, and did not show any difference between groups and time.

Table 1. Analgesic protocol group, breed, age, weight, spinal cord compression site and need for analgesic rescue in dogs with intervertebral disc disease undergoing hemilaminectomy

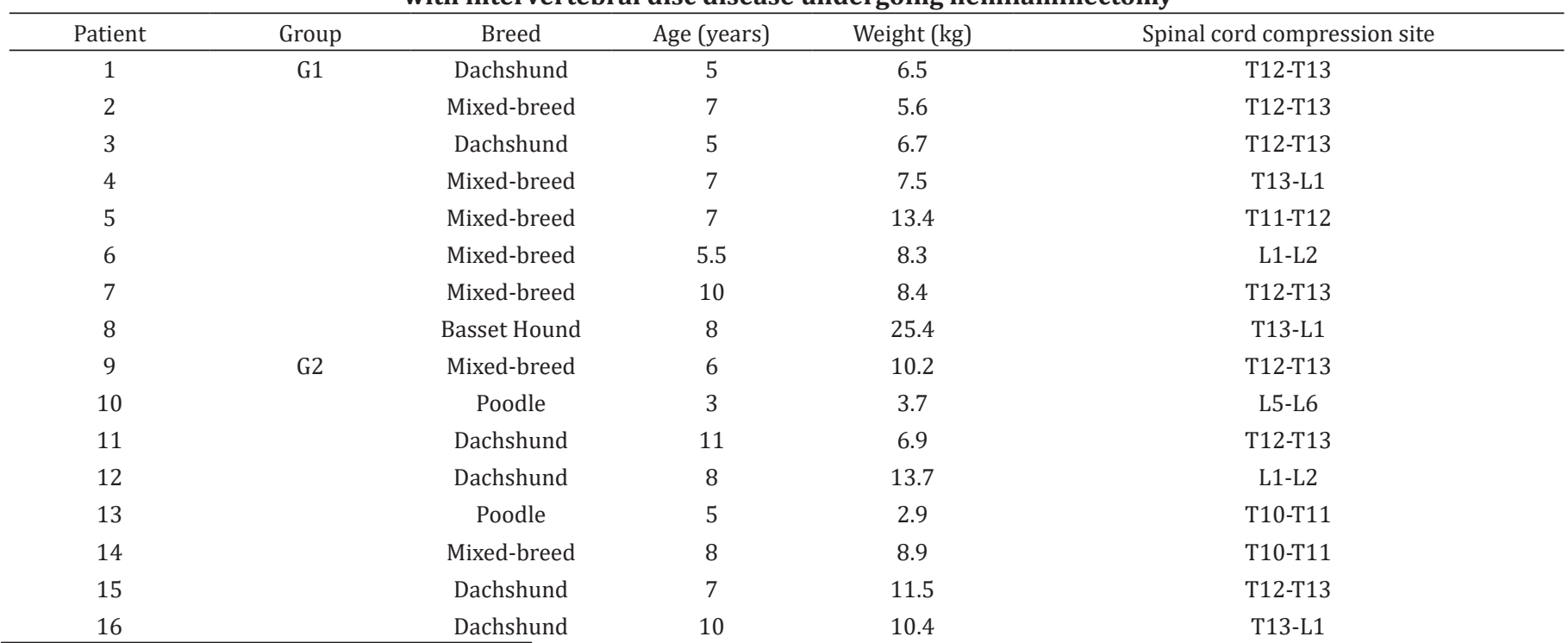

G1 = methadone, meloxicam and dipyrone, G2 = meloxicam and dipyrone, $\mathrm{T}=$ thoracic vertebra, $\mathrm{L}=$ lumbar vertebra; All patients were paraplegic with preserved nociception; No patient needed analgesic rescue 
in this study (6), occurred in animal 8 (G1; T0, T4, T6, T8, T10, T12, T18, T20, T22, T24).

As for the adverse effects caused by the analgesic protocols, three patients presented hyporexia or anorexia (Patients 1, 7 and 11), while four patients demonstrated panting (Patients 4, 8, 9 and 14) (Table 1). On the other hand, no dog presented vomiting, cardiac or respiratory depression and constipation up to 48 hours postoperatively.

\section{DISCUSSION}

This study demonstrated that an analgesic protocol without any opioid medication can provide adequate postoperative analgesia in dogs undergoing hemilaminectomy and disc fenestration due to IVDE. It supports the analgesic effects of dipyrone, meloxicam, and cryotherapy for these procedures, and suggests the hypothesis that the main source of pain in these patients is the meningeal, nerve root, annulus fibrosus, and ligamentous structures compression by the extruded disc, which ceases after surgery. It is also important to note that the analgesic protocols not only aim to relieve the pain of the surgical procedure, but the IVDE itself. The presence of intervertebral disc material in the vertebral canal after the surgery, especially on the nerve roots, may contribute to the persistence of pain (Brisson 2017), which probably did not occur in the dogs of this study, as they presented pain scores below $50 \mathrm{~mm}$ in all assessments performed (Fig.1-2).

A detailed analysis of the CMPS-SF showed that the changes found in Patient 8 were possibly due to behavioral factors. Although the CMPS-SF is a validated method of pain assessment in dogs, some of its criteria can be read as pain and interfere with the results (anxious and restless animals manifest behaviors that may be confused with pain by the requirements described for scoring on the scale) (Barker et al. 2013). Conzemius et al. (1997) reported the subjectivity within pain scales as being a negative factor in the pain assessment, while Aghighi et al. (2012) recognized a limitation of the VAS and the CMPS-SF in clearly detecting the analgesic effects of the drugs used in their experiment. There were no complications in the perioperative period of Patients 8 and 15 , or any other patient, that could justify the VAS and the CMPS-SF dissenting scores. There was no need for analgesic rescues in the intraoperative period.

The median pain scores prior to the surgical procedure (Baseline) in the VAS were statistically higher $(p<0.05)$ when compared to T28 (G2), T36 (G1), T40 (G1), T44 (G1) and T48 (G1) assessment times. For the CMPS-SF, the Baseline was higher when compared to T28 (G2). This result supports our hypothesis that pain caused by disc extrusion can be considered the main painful stimulus and it is interrupted by decompressive surgery, as reported by Giudice et al. (2017). Also, there is a tendency for the highest scores to occur in the first 24 postoperative hours when compared to the 24 to 48 postoperative hours (Fig.1-2). Therefore, greater attention should be paid to analgesia in the first 24 hours. In the T0 assessment, some patients had not yet had complete anesthetic recovery, thus scoring more in the CMPS-SF (e.g. T28, G2), especially in section $\mathrm{D}$. The early T0 assessment, 30 minutes after the end of surgery, was established to avoid potential pain after the end of the Fentanyl infusion, and to standardize the period between the end of the opioid infusion and the first postoperative assessment.
Analgesia was adequate in both groups (G1, G2). The use of meloxicam and dipyrone alone were effective in the postoperative analgesia. This finding puts into question the need of opioids in the postoperative period of decompressive spinal surgery, as well as the degree of postoperative pain, considered intense by several authors (Fantoni \& Mastrocinque 2010, Mathews et al. 2014, Carroll \& Martin 2015). As in the present study, others have studied the response of NSAIDs and dipyrone in different surgeries, obtaining satisfactory results. Gruet et al. (2011) had tested the efficacy of meloxicam and robenacoxib unassociated with opioids in the postoperative analgesia of dogs undergoing orthopedic surgeries, concluding that they were effective. Another study conducted by Deneuche et al. (2004) demonstrated the efficacy of pre and peri-operative administration of meloxicam or ketoprofen in analgesia after orthopedic surgeries in the first 24 hours. Dipyrone has already been tested and proved to be effective in the postoperative analgesia of dogs undergoing several procedures such as open and video assisted ovariohysterectomy (Imagawa et al. 2011, Kalchofner Guerrero et al. 2015, Dalmolin et al. 2020), and total hip replacement (Rudolff 2011). Similar favorable results have already been found in the human medicine literature (Hearn et al. 2016). The wide range of studies with NSAIDs and dipyrone, presenting good results in different procedures and levels of painful stimulus, demonstrates the good applicability of these drugs, sometimes underestimated in clinical practice.

Another undervalued analgesic method in veterinary practice is cryotherapy, used throughout the postoperative period in our patients. Its recognized analgesic and antiinflammatory action may have helped allopathic medications to fight pain, contributing to positive results (Millis 2004, Drygas et al. 2011).

In the study by Ripplinger et al. (2018) the main adverse effects in dogs that underwent spinal surgery and who were administered morphine, methadone or tramadol in postoperative analgesia were hypophagia, anorexia, and vomiting. Similar results were found in a prospective study in which methadone was used every four hours or as needed according to the CMPSSF (Bini et al. 2018). The analgesic protocol used by Schmierer et al. (2020), based on pregabalin and fentanyl patches, also induced adverse effects like vomiting and sedation in some of its dogs. In our study, three of the dogs that had adverse effects did not receive methadone in their protocol, revealing that these changes may be behavioral and individual.

The fact that analgesic rescues were not required in this study demonstrates that the two protocols with or without methadone provided adequate analgesia, with few adverse effects. Thus, these protocols can be applied safely in both hospital or home environment.

As a limitation of this study we can mention the absence of a control group without the use of analgesics, as some studies have recommended (Lascelles \& Waterman 1997). In this study, the authors chose not to use a group without analgesia due to ethical issues and the guarantee of animal welfare. Another limitation is the intrinsic subjectivity of the chosen pain scales, mitigated by the experienced observers, as shown by the correlation test. The use of other pain assessment mechanisms such as von Frey filaments or pressure algometers should be considered in future studies. 
We suggest the development of more prospective, multicenter studies, with different opioid-free protocols, routes of administration and surgical techniques, to reinforce the information found in our research, mainly referring to the classification of postoperative pain in decompressive surgeries of the spine.

\section{CONCLUSION}

Analgesic protocols based on meloxicam and dipyrone, with or without methadone, provided analgesia during the initial 48 hours postoperatively in patients with intervertebral disc extrusion (IVDE) undergoing hemilaminectomy and disc fenestration.

Acknowledgements.- This study was supported and financed by the "Conselho Nacional de Desenvolvimento Científico e Tecnológico" (CNPq) Brazil, process number 307120-2017-1 and the "Coordenação de Aperfeiçoamento de Pessoal de Nível Superior" (CAPES) Brazil.

Conflict of interest statement.- The authors declare having no conflicting interests.

\section{REFERENCES}

Aghighi S.A., Tipold A., Piechotta M., Lewczuk P. \& Kästner S.B.R. 2012. Assessment of the effects of adjunctive gabapentin on postoperative pain after intervertebral disc surgery in dogs. Vet. Anaesth. Analg. 39(6):636-646. <https://dx.doi.org/10.1111/j.1467-2995.2012.00769.x><PMid:22882632>

Barker J.R., Clark-Price S.C. \& Gordon-Evans W.J. 2013. Evaluation of topical epidural analgesia delivered in gelfoam for postoperative hemilaminectomy pain control. Vet. Surg. 42(1):79-84. <https://dx.doi.org/10.1111/j.1532950X.2012.01082.X><PMid:23216100>

Bini G., Vettorato E., Gennaro C.D. \& Corletto F. 2018. A retrospective comparison of two analgesic strategies after uncomplicated tibial plateau levelling osteotomy in dogs. Vet. Anaesth. Analg. 45(4):557-565. <https://dx.doi. org/10.1016/j.vaa.2017.11.005> <PMid:29853415>

Brisson B.A. 2017. Intervertebral disc fenestration, p.191-198. In: Shores A. \& Brisson B.A. (Eds), Current Techniques in Canine and Feline Neurosurgery. Wiley Blackwell, New Jersey.

Carroll L.G. \& Martin D.D. 2015. Pacientes críticos e traumatismo, p.10701089. In: Tranquilli W.J., Greene S.A. \& Robertson S.A. (Eds), Veterinary Anesthesia and Analgesia: the fifth edition of Lumb and Jones. 5th ed. Wiley Blackwell, Ames.

Conzemius M.G., Hill C.M., Sammarco J.L. \& Perkowsi S.Z. 1997. Correlation between subjective and objective measures used to determine severity of postoperative pain in dogs. J. Am. Vet. Med. Assoc. 210(11):1619-1622. <PMid:9170089>

Dalmolin F., Oliveira M.T., Pinto Filho S.T.L., Vaz M.A.B., Bertoletti B., Pohl V.H., Ferranti J.P.S., Hartmann H.F. \& Brun M.V. 2020. Metamizol and scopolamine for conventional or two-port laparoscopic-assisted ovariohysterectomy in dogs. Acta Sci. Vet. 48:1741. <https://dx.doi.org/10.22456/16799216.100679>

Deneuche A.J., Dufayet C., Goby L., Fayolle P. \& Desbois C. 2004. Analgesic comparison of meloxicam or ketoprofen for orthopedic surgery in dogs. Vet. Surg. 33(6):650-660. <https://dx.doi.org/10.1111/j.1532-950X.2004.04088.x> <PMid:15659022>

Drygas K.A., McClure S.R., Goring R.L., Pozzi A., Robertson S.A. \& Wang C. 2011. Effect of cold compression therapy on postoperative pain, swelling, range of motion, and lameness after tibial plateau leveling osteotomy in dogs. J. Am. Vet. Med. Assoc. 238(10):1284-1291. <https://dx.doi.org/10.2460/ javma.238.10.1284><PMid:21568773>
Fantoni D.T. \& Mastrocinque S. 2010. Fisiopatologia e controle da dor aguda, p.522-544. In: Fantoni D.T. \& Cortopassi S.R.G. (Eds), Anestesia em Cães e Gatos. $2^{\underline{a}}$ ed. Roca, São Paulo.

Forterre F., Konar M., Spreng D., Jaggy A. \& Lang J. 2008. Influence of intervertebral disc fenestration at the herniation site in Association with hemilaminectomy on recurrence in chondrodystrophic dogs with thoracolumbar disc disease: a prospectibe MRI study. Vet. Surg. 37(4):399-405. <https://dx.doi.org/10.1111/j.1532-950X.2008.00394.X> $<$ PMid:18564265>

Giudice E., Barillaro G., Crinò C., Alaimo A., Macrì F. \& Di Pietro S. 2017. Postoperative pain in dogs undergoing hemilaminectomy: Comparison of the analgesic activity of buprenorphine and tramadol. J. Vet. Behav. 19:45-49. <https://dx.doi.org/10.1016/j.jveb.2017.02.003>

Gruet P., Seewald W. \& King J.N. 2011. Evaluation of subcutaneous and oral administration of robenacoxib and meloxicam for the treatment of acute pain and inflammation associated with orthopedic surgery in dogs. Am. J. Vet. Res. 72(2):184-193. <https://dx.doi.org/10.2460/ajvr.72.2.184> $<$ PMid:21281192>

Hearn L., Derry S. \& Moore R.A. 2016. Single dose dipyrone (metamizole) for acute postoperative pain in adults. Cochrane Database Syst. Rev. 20(4):CD011421.<https://dx.doi.org/10.1002/14651858.CD011421.pub2> $<$ PMid:27096578>

Imagawa V.H., Fantoni D.T., Tatarunas A.C., Mastrocinque S., Almeida T.F., Ferreira F. \& Posso I.P. 2011. The use of different doses of metamizol for post-operative analgesia in dogs. Vet. Anaesth. Analg. 38(4):385-393. <https://dx.doi.org/10.1111/j.1467-2995.2011.00617.x><PMid:21627755>

Kalchofner Guerrero K.S., Schwarz A., Wuhrmann R., Feldmann S., Hartnack S. \& Bettschart-Wolfensberger R. 2015. Comparison of a new metamizole formulation and carprofen for extended post-operative analgesia in dogs undergoing ovariohysterectomy. Vet. J. 204(1):99-104. <https://dx.doi. org/10.1016/j.tvjl.2015.01.028> <PMid:25744803>

Kukanich B. \& Wiese A.J. 2015. Opioids, p.207-226. In: Tranquilli W.J., Greene S.A. \& Robertson S.A. (Eds), Veterinary Anesthesia and Analgesia: the fifth edition of Lumb and Jones. 5th ed. Wiley Blackwell, Ames.

Lascelles D. \& Waterman A. 1997. Analgesia in cats. In Practice 19(4):203213. <https://dx.doi.org/10.1136/inpract.19.4.203>

Mathews K., Kronen P.W., Lascelles D., Nolan A., Robertson S., Steagall P.Vm., Wright B. \& Yamashita K. 2014. Guidelines for recognition, assessment and treatment of pain. J. Small Anim. Pract. 55(6):E10-E68. <https://dx.doi. org/10.1111/jsap.12200><PMid:24841489>

Millis D.L. 2004. Getting the dog moving after surgery. J. Am. Anim. Hosp. Assoc. 40(6):429-436. <https://dx.doi.org/10.5326/0400429><PMid:15533962>

Muir III W.W. 2015. Overview of drugs administered to treat pain, p.11114. In: Gaynor J.S. \& Muir III W.W. (Eds), Handbook of Veterinary Pain Management. Elsevier, Missouri.

Platt S.R. 2004. Neck and back pain, p.202-213. In: Platt S.R. \& Olby N.J. (Eds), BSAVA Manual of Canine and Feline Neurology. BSAVA, Gloucester.

Re Bravo V., Aprea F., Bhalla R.J., De Gennaro C., Cherubini G.B., Corletto F. \& Vettorato E. 2018. Effect of 5\% transdermal lidocaine patches on postoperative analgesia in dogs undergoing hemilaminectomy. J. Small Anim. Pract. 60(3):161-166. <https://dx.doi.org/10.1111/jsap.12925> $<$ PMid:30175446>

Reid J., Nolan A.M., Hughes J.M.L., Lascelles D., Pawson P. \& Scott E.M. 2007. Development of the short-form Glasgow Composite Measure Pain Scale (CMPS-SF) and derivation of an analgesic intervention score. Anim. Welf. 16(S):97-104.

Ripplinger A., Aiello G., Chaves R.O., Andrades A.O., Beckmann D.V., Polidoro D., Soares A.S. \& Mazzanti A. 2018. Efeitos adversos da morfina, metadona e tramadol no pós-operatório de cães submetidos à cirurgia da coluna vertebral: 180 casos (2011-2016). Pesq. Vet. Bras. 38(7):1431-1437. <https://dx.doi.org/10.1590/1678-5150-PVB-5307> 
Rudolff A.S. 2011. Evaluation of Metamizole and Carprofen as postoperative analgesics in canine total hip replacement. Doctoral Dissertation, der Tierärztlichen Fakultät der Ludwig-Maximilians-Universität. 101p.

Schmierer P.A., Tünsmeyer J., Tipold A., Hartnack-Wilhelm S., Lesczuk P. \& Kastner S.B.R. 2020. Randomized controlled trial of pregabalin for analgesia after surgical treatment of intervertebral disc disease in dogs. Vet. Surg. 49(5):905-913. <https://dx.doi.org/10.1111/vsu.13411>
Shores A. 2017. Thoracolombar hemilaminectomy, p.179-182. In: Shores A. \& Brisson B.A. (Eds), Current Techniques in Canine and Feline Neurosurgery. Wiley Blackwell, New Jersey.

Taylor-Brown F.E., Cardy T.J.A., Liebel F.X., Garosi L., Kenny P.J., Volk H.A. \& De Decker S. 2015. Risk factors for early post-operative neurological deterioration in dogs undergoing a cervical dorsal laminectomy or hemilaminectomy: 100 cases (2002-2014). Vet. J. 206(3):327-331. <https://dx.doi.org/10.1016/j.tvjl.2015.10.010> <PMid:26542365> 